\title{
Chorioamnionitis Induced Hepatic Inflammation and Disturbed Lipid Metabolism in Fetal Sheep
}

\author{
VEERLE BIEGHS, EVI VLASSAKS, ANNE CUSTERS, PATRICK J. VAN GORP, MARION J. GIJBELS, AALT BAST, \\ OTTO BEKERS, LUC J. I. ZIMMERMANN, DIETER LÜTJOHANN, J.-WILLEM VONCKEN, A. W. DANILO GAVILANES, \\ BORIS W. KRAMER, AND RONIT SHIRI-SVERDLOV
}

\begin{abstract}
Department of Molecular Genetics and Pathology [V.B., P.J.G., M.J.G., J.-W.V., R.S.-S.), Maastricht University, Maastricht 6200 MD, The Netherlands; Departments of Pharmacology and Toxicology [A.B.], Pediatrics [E.V., A.C., L.J.I.Z., A.W.D.G., B.W.K.], and Clinical Chemistry [O.B.], Maastricht University Medical Center, Maastricht 6202 AZ, The Netherlands; Institute of Clinical Chemistry and Pharmacology [D.L.], University of Bonn, 53113 Bonn, Germany
\end{abstract}

\begin{abstract}
Chorioamnionitis frequently induces a fetal inflammatory response syndrome (FIRS), characterized by an elevation of proinflammatory mediators and systemic inflammation. Although there is increasing evidence that inflammation and lipid metabolism influence each other, the effects of chorioamnionitis-induced FIRS on fetal lipid homeostasis are currently not known. Accordingly, we hypothesize that chorioamnionitis induces an inflammatory response in the fetal liver, consequently leading to metabolic disturbances. Chorioamnionitis was induced by intra-amniotic injection of $10 \mathrm{mg}$ endotoxin (control) for $2 \mathrm{~d}$ or $2 \mathrm{wk}$ before delivery. Saline injections were given to controls. The effect of chorioamnionitis on hepatic inflammation and metabolic parameters was analyzed in ovine fetuses at the GA of $125 \mathrm{~d}$ (normal GA $=150 \mathrm{~d}$ ). We found that $2 \mathrm{~d}$ after the endotoxin injections, inflammatory markers were significantly higher compared with controls. In addition, lipid and glucose metabolism were disturbed in response to endotoxin. Moreover, the antioxidant state capacity was reduced, and hepatic damage was apparent. Two weeks after the endotoxin injections, the fetal livers were still inflamed and had higher glucose concentrations in the blood. In addition, the levels of markers for hepatic damage (alanine aminotransferase and aspartate aminotransferase) were increased. In conclusion, chorioamnionitis induces liver inflammation leading to metabolic disturbances in the fetus. (Pediatr Res 68: 466-472, 2010)
\end{abstract}

$\mathrm{P}$ reterm delivery is a major problem in reproductive medicine today. Currently, $\sim 10 \%$ of all deliveries are preterm (1). Irrespective of the progress in neonatal care, preterm delivery is still the most important cause of neonatal death and long-term neurological morbidity. In addition, most interventions to prevent preterm birth are unsuccessful $(2,3)$.

Chorioamnionitis, defined as inflammation of the amniotic fluid and fetal membranes caused by bacterial endotoxin, is a common pregnancy complication and is associated with preterm birth (4). At least $60 \%$ of all preterm births below $25 \mathrm{wk}$ of gestation have mothers who suffer from chorioamnionitis $(2,5)$. Chorioamnionitis frequently causes a fetal inflammatory response syndrome (FIRS), which is characterized by an

Received February 4, 2010; accepted July 17, 2010.

Correspondence: Boris W. Kramer, M.D., Ph.D., Department of Pediatrics, Maastricht University Medical Center, Postbus 5800, 6200 MD Maastricht, The Netherlands; e-mail: b.kramer@mumc.nl

Supported by Grant VENI 916.76.070 (2006/00496) [M.W.] VENI 016.096.141 [B.W.K.] and a Grant WO 08-16 of the Maag Lever Darm Stichting (MLDS).

V.B., E.V., and A.C. contributed equally to this work. elevation of proinflammatory mediators and systemic inflammation (6). So far, most studies in the field of chorioamnionitis and FIRS have focused on the effects on lungs and brain (6). However, the effects of chorioamnionitis-induced FIRS on the liver have thus far not been investigated. The liver is a central organ in an organism's metabolism, and damage to the liver may play an important role in the development of metabolic diseases $(7,8)$. Accordingly, we hypothesized that chorioamnionitis induced an inflammatory response in the fetal liver, which would lead to fetal metabolic disturbances. This hypothesis is in line with several observations indicating that inflammation and lipid metabolism influence each other (9). Besides the finding that lipids can induce an inflammatory state, inflammation itself has been described to induce changes in lipid metabolism (9).

To test our hypothesis, we examined whether intra-amniotic endotoxin injection in sheep, an established model of chorioamnionitis (10-16), induced inflammation and lipid changes in the fetal liver. Both short-term (2 d) effects and long-term ( $2 \mathrm{wk}$ ) effects of endotoxin-induced chorioamnionitis were studied. The livers of ovine fetuses were analyzed at birth at a GA of $125 \mathrm{~d}$ (comparable with a GA of $28 \mathrm{wk}$ in humans; normal ovine $\mathrm{GA}=150 \mathrm{~d}$ ) for hematopoietic activity, antiinflammatory capacity, glycogen storage, inflammation, and cell damage. In addition, we studied the relationship between hepatic inflammation and lipid levels in the liver and glucose concentrations in plasma.

\section{MATERIALS AND METHODS}

Animals, intra-amniotic injections, and tissue processing at delivery. The study protocol was approved by and was performed according to the guidelines of the Animal Care Committee of the University of Maastricht, The Netherlands. Fifteen time-mated Texel ewes, bearing both singletons and twins, were randomly assigned to receive a single dose of $10 \mathrm{mg}$ endotoxin (Escherichia coli 055:B5; Sigma Chemical Co. Chemical, St. Louis, MO) or the equivalent volume of saline for controls by ultrasound guided intraamniotic injections (10). The influence of singleton/twin and gender on the analyzed variables was ruled out by using multivariate ANOVA. Both short-

Abbreviations: ALT, alanine aminotransferase; AST, aspartate aminotransferase; FIRS, fetal inflammatory response syndrome; GGT, gamma-glutamyltranferase; GST, glutathione S-transferase; H/E, hematoxylin and eosin; MPO, myeloperoxidase 
and long-term effects of chorioamnionitis induced by intra-amniotic endotoxin injections were studied $2 \mathrm{~d}(n=5 ; n=5$ for controls after saline injection) and $2 \mathrm{wk}$ ( $n=7 ; n=7$ for controls after saline injection) before the Caesarean section delivery at the GA of $125 \mathrm{~d}$ (term being $150 \mathrm{~d}$; Fig. 1). At birth, a cord blood arterial sample was collected followed by a lethal injection of pentobarbital sodium via the umbilical vein. Samples of the left liver were either fixated in $4 \%$ formaldehyde or snap frozen in liquid nitrogen for further analysis.

Immunohistochemistry and histological analysis. Liver tissue was fixed in formaldehyde, embedded in paraffin, and cut in $3 \mu \mathrm{m}$ sections. Hepatic inflammation and hematopoiesis were evaluated after hematoxylin and eosin $(\mathrm{H} / \mathrm{E})$ staining in response to endotoxin-induced chorioamnionitis. Whole sections were analyzed for inflammation and scored in a blinded manner by a specialized animal pathologist. The sections from each animal were scored as zero if they had no inflammatory cells present in tissue, one for a few inflammatory cells (1-20 cells), two for moderate cell infiltration (21-40 cells), three for a large number of inflammatory cells (41-60 cells), and four if inflammation was spread all over in the tissue ( $>61$ cells) (10). The sections were also scored for hematopoiesis, using the following semiquantitative scale: grade 0 (none), grade 1 (mild), grade 2 (moderate), and grade 3 (severe) (17). The specificity of the inflammatory cells in the fetal liver tissue was determined by immunohistochemical staining for T-lymphocytes (CD3) and for myeloperoxidase (MPO) (18). Endogenous peroxidase activity was blocked by incubation in hydrogen peroxide. Nonspecific binding sites were blocked with serum. After antigen retrieval, CD3-positive T-lymphocytes were stained with a polyclonal rabbit anti-human CD3 antibody (DAKO A0452; dilution 1:200). Polyclonal rabbit anti-human MPO (DAKO A0398; dilution 1:500) was used as primary antibody to identify MPO-positive cells. Biotinylated polyclonal swine anti-rabbit IgG (DAKO E0353; dilution 1:200/ 1:500) was applied as secondary antibody. After adding StrepABComplex/ HRP (DAKO KO377), staining was performed with 3-amino-9-ethylcarbazole, and sections were counterstained with hematoxylin.

Sections were photographed at $200 \times$ magnification using a Nikon digital camera DMX1200 and ACT-1 v2.63 software from the Nikon Corporation. For the CD3 and MPO immunohistochemical staining, cell numbers were counted in six randomly selected microscopical views and were noted as cells per square millimeter.

Glycogen content was detected in the fetal livers by a Periodic Acid Schiff (PAS) staining. Paraffin sections were incubated in $1 \%$ periodic acid. Counterstaining was performed with hematoxylin. The relative glycogen content of

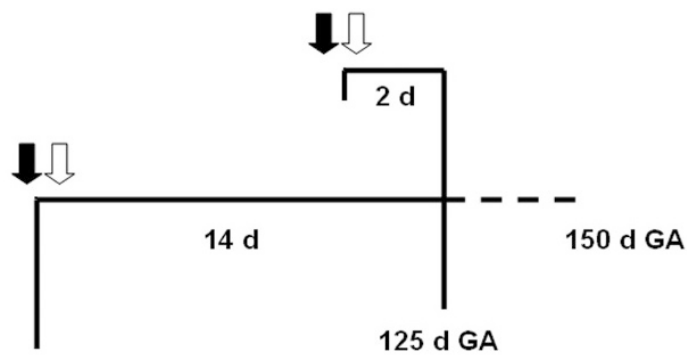

Intra-amniotic endotoxin

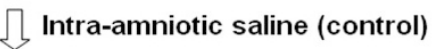

Figure 1. Schematic overview of the experimental design. Chorioamnionitis was induced by intra-amniotic injections of endotoxin $2 \mathrm{~d}(\mathrm{GA}=123 \mathrm{~d}, n=$ 5) and $2 \mathrm{wk}(\mathrm{GA}=111 \mathrm{~d}, n=7)$ before delivery at GA $125 \mathrm{~d}$ (normal GA = $150 \mathrm{~d})$. Saline injections were given $2 \mathrm{~d}(n=5)$ or 2 wk before delivery $(n=$ 7). Endotoxin injections are indicated as black arrows, and saline injections are indicated as white arrows. individual livers was estimated from the PAS staining intensity in a blinded fashion, which was rated as negative (score 0), minimal (score 1), moderate (score 2), or severe (score 3).

To investigate fat deposition in the liver, frozen $7-\mu \mathrm{m}$ thick sections were stained with oil red $\mathrm{O}$. Briefly, liver cryosections were fixed for $60 \mathrm{~min}$ in $3.7 \%$ formaldehyde solution and stained with $0.2 \%$ oil red $\mathrm{O}$ in $60 \%$ triethyl-phosphate for $30 \mathrm{~min}$. Sections were counterstained with Mayer's hematoxylin, washed with running tab water, and covered with coverslip using $10 \%$ glycerol in PBS.

RNA extraction and RT-PCR. Total RNA was isolated from frozen liver samples by using Tri-reagent of Sigma Chemical Co., as previously described (8). All applications were done according to manufacturer's protocols. Reverse transcription was performed using the iScript cDNA synthesis kit (Bio-Rad, Hercules, CA) according to manufacturer's instructions. Real-time PCR was performed on a Bio-Rad MyIQ with the IQ5 v2 software using the IQ SYBR Green Supermix with fluorescein (Bio-Rad) and $10 \mathrm{ng}$ of cDNA. Primers for target genes IL- $1 \beta$, IL-8, TNF, and glutathione S-transferase (GST) were developed using Primer Express version 2.0 (Applied Biosystems, Foster City, CA) using default settings. To standardize for the amount of cDNA, cyclophylin A (peptidylprolyl isomerase A, PPIA) was used as housekeeping gene. Primer sequences are given in Table 1 . The liver real-time PCR results were obtained using the relative standard curve method.

Antioxidant capacity. The trolox equivalent antioxidant capacity (TEAC) indicates the total antioxidant status. It is an assay to relate the free radical scavenging properties of a solution or a compound to that of the synthetic antioxidant trolox. The assay was performed as previously described with minor modifications (19). In short, a 2,2'-azino-bis(3-ethylbenzthiazoline-6sulfonic acid (ABTS)) solution was freshly prepared. This solution was heated at $70^{\circ} \mathrm{C}$ for $\sim 10 \mathrm{~min}$. The absorbance at $734 \mathrm{~nm}$ was determined every 2 to 3 min to evaluate the ABTS formation. At an absorbance between 0.6 and 0.7 , the reaction was stopped by cooling the solution on ice.

Liver lipid analysis. Approximately $50 \mathrm{mg}$ of frozen liver tissue was homogenized (8). Protein content was measured using the bicinchoninic acid method (Pierce, Rockford, AL). Triglycerides and total cholesterol content were measured according to manufacturer's instructions on a Benchmark 550 Micro-plate reader (Bio-Rad).

Plasma parameters. Triglycerides, total cholesterol, and HDL (C) have been determined on a Beckman Coulter Synchron LX20 PRO Clinical Chemistry analyzer (Beckman Coulter, Fullerton, CA). The measurements have been validated in adult and fetal sheep. LDL (C) has been calculated by the Friedewald equation $(20,21)$. This equation estimates LDL (C) from the measurements of total cholesterol, triglycerides, and HDL (C): LDL (C) = total cholesterol - [triglycerides/2.2 + HDL (C)] (22).

The glucose concentration was determined by an oxygen rate method using the oxidation of glucose to gluconolactone catalyzed by glucose oxidase at an enzyme electrode. Gamma-glutamyltranferase (GGT), aspartate aminotransferase (AST), and alanine aminotransferase (ALT) have been determined on a Beckman Coulter Synchron LX20 PRO Clinical Chemistry analyzer (Beckman Coulter, Fullerton), where the activity was measured by an enzymatic rate method. The rate of change in absorbance, which is caused by the enzymatic reaction, is directly proportional to the activity of GGT, ALT, and AST in the sample and is used by the Synchron system to calculate and express the respective activity.

Data analysis. Data were statistically analyzed using Statistical Package for Social Sciences (SPSS 15.0 Software). Comparisons between controls and endotoxin-injected groups were performed by $t$ test and in addition multivariate one-way ANOVA with gender and singleton/twin as covariates. Significant effects were analyzed by post hoc Bonferroni corrections. Scoring of hematopoietic, inflammatory cells, and glycogen was calculated by Pearson's $\chi^{2}$ test. Results are presented as means $\pm \mathrm{SD}$, and a $p<0.05$ was considered as statistically significant. The symbols, $* / \|$, indicate significant differences between saline and endotoxin-injected groups with $* p<0.05$; * $p<0.01$; and $\| p<0.001$.

Table 1. Primer sequences used in RT-PCR

\begin{tabular}{lll}
\hline Primer & \multicolumn{1}{c}{ Forward } & \multicolumn{1}{c}{ Reverse } \\
\hline PPIA $*$ & TTATAAAGGTTCCTGCTTTCACAGAA & ATGGACTTGCCACCAGTACCA \\
IL-1 $\beta$ & AGAATGAGCTGTTATTTGAGGTTGATG & GTGAGAAATCTGCAGCTGGATGT \\
IL-8 & TTCCAAGCTGGCTGTTGCT & GTGGAAAGGTGTGGAATGTGTTT \\
TNF- $\alpha$ & CATCTTCTCAAGCCTCAAATAACAA & TGCGAGTAGATGAGGTAAAGCCC \\
GST & CTACATTGCCACCAAATACAACCT & AATCTGCCACCCCCTCTGA \\
\hline
\end{tabular}

\footnotetext{
* Housekeeping gene.
} 


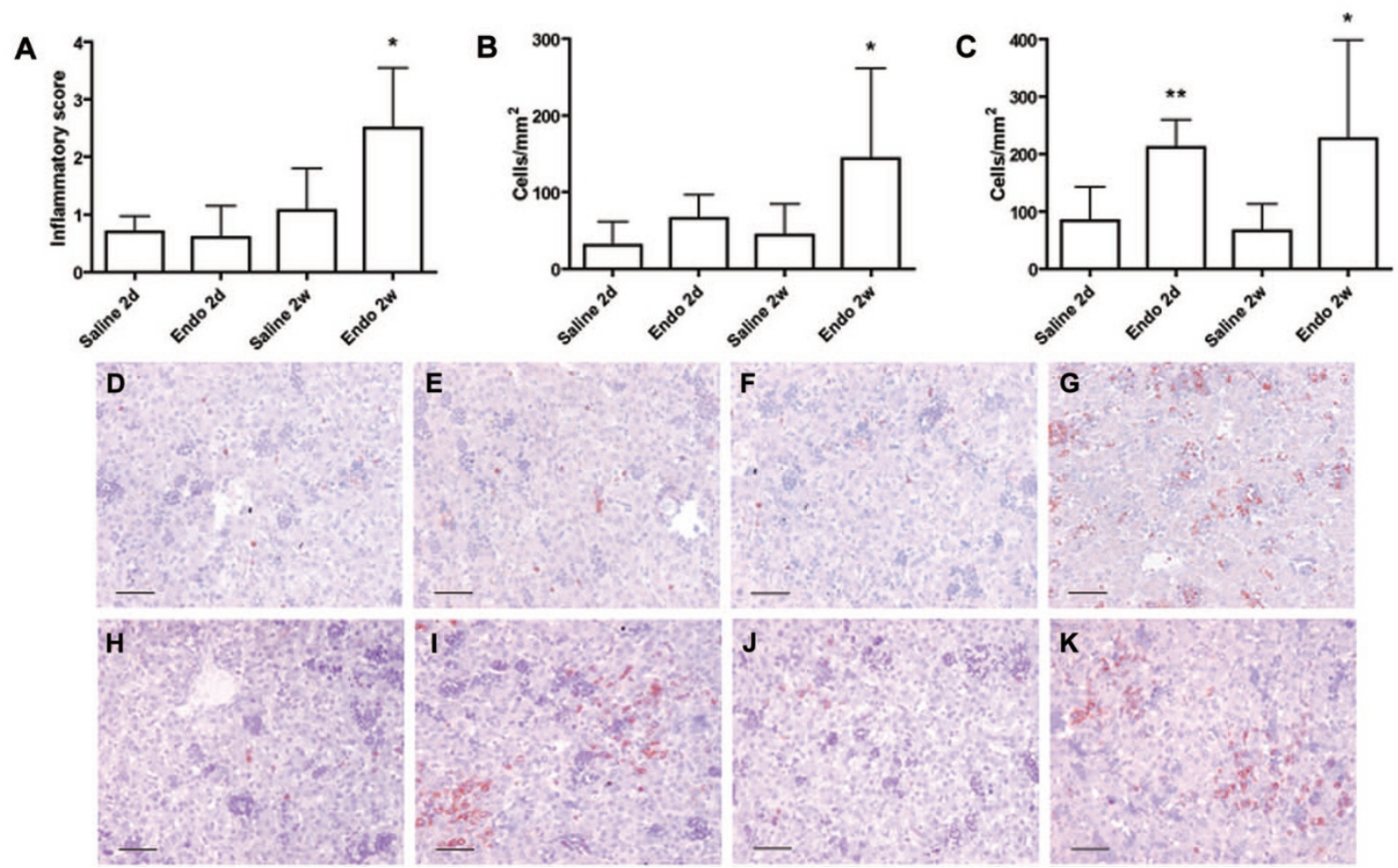

Figure 2. Hepatic inflammation. Inflammatory score of H/E-stained liver sections from saline- and endotoxin-exposed animals $(A)$. T-lymphocyte staining $(B)$ and MPO staining $(C)$. Liver paraffin sections were stained against T-lymphocytes (CD3) and MPO, respectively. Results are expressed as number of cells per square millimeter. Representative pictures $(\times 200$ magnification; scale bar $100 \mu \mathrm{m})$ of the CD3 staining for the saline $2 \mathrm{~d}(D)$, endotoxin $2 \mathrm{~d}(E)$, saline $2 \mathrm{wk}$ $(F)$, and endotoxin $2 \mathrm{wk}(G)$ exposed animals, respectively. Representative pictures (200× magnification; scale bar $100 \mu \mathrm{m})$ of the MPO staining for the saline $2 \mathrm{~d}(H)$, endotoxin $2 \mathrm{~d}(I)$, saline $2 \mathrm{wk}(J)$, and endotoxin $2 \mathrm{wk}(K)$ exposed animals, respectively. $* p<0.05$ and $* * p<0.01$ significant difference from saline-injected group.

Table 2. Representation of hematopoietic score, relative IL-8 mRNA expression, and hepatic cholesterol and triglyceride levels in the four different groups

\begin{tabular}{lcccc}
\hline \multicolumn{1}{c}{ Group } & Hematopoietic score $(0-3)$ & $\begin{array}{c}\text { Relative IL-8 } \\
\text { mRNA expression }\end{array}$ & $\begin{array}{c}\text { Hepatic cholesterol } \\
(\mathrm{mg} / \mathrm{mg} \text { protein) }\end{array}$ & $\begin{array}{c}\text { Hepatic triglycerides } \\
(\mathrm{mg} / \mathrm{mg} \text { protein })\end{array}$ \\
\hline Saline 2 d & $2.40 \pm 0.55$ & $1.00 \pm 0.36$ & $0.02 \pm 0.006$ & $0.07 \pm 0.02$ \\
Endotoxin 2 d & $2.50 \pm 0.58$ & $1.09 \pm 0.21$ & $0.03 \pm 0.01$ & $0.07 \pm 0.03$ \\
Saline 2 wk & $2.67 \pm 0.52$ & $1.00 \pm 0.27$ & $0.02 \pm 0.003$ & $0.06 \pm 0.02$ \\
Endotoxin 2 wk & $3.00 \pm 0.63$ & $0.94 \pm 0.21$ & $0.02 \pm 0.003$ & $0.06 \pm 0.03$ \\
\hline
\end{tabular}

Values are expressed as mean $\pm \mathrm{SD}$.

\section{RESULTS}

Hepatic inflammation and hematopoiesis. H/E-stained liver sections from control animals and animals that received endotoxin $2 \mathrm{~d}$ before delivery showed no differences in inflammatory cell infiltration (Fig. 2). However, an increased level of infiltrated inflammatory cells was detected $2 \mathrm{wk}$ after endotoxin exposure (Fig. 2A). There were no significant differences in hematopoiesis between the four groups (Table 2).

Consistent with the results of the H/E staining, CD3positive T-lymphocytes were significantly increased in the livers of animals that received endotoxin $2 \mathrm{wk}$ before delivery (Fig. 2B). Remarkably, most CD3-positive T-lymphocytes were positioned in the hematopoietic clusters (Fig. $2 D-G$ ). An interesting observation was the increase in the number MPOpositive cells both $2 \mathrm{~d}$ and $2 \mathrm{wk}$ after the endotoxin injections compared with controls (Fig. 2C). Unlike the CD3-positive
T-lymphocytes, the MPO-positive cells were not located in between the hematopoietic clusters (Fig. 2H-K).

Expression profiling of genes involved in inflammation. To investigate the hepatic response to endotoxin-induced chorioamnionitis in more detail, mRNA levels of TNF and IL- $1 \beta$ were determined. TNF and IL- $1 \beta$ mRNA levels rapidly increased in the fetal liver of animals that were killed $2 \mathrm{~d}$ after the endotoxin injection. Two weeks after the endotoxin exposure, cytokine mRNA levels returned to basal levels (Fig. 3). The mRNA levels for the neutrophil chemoattractant IL-8 did not change in the fetal liver after fetal exposure to endotoxin (Table 2).

Metabolic changes after endotoxin-induced chorioamnionitis. Because the liver has indispensable functions in lipid homeostasis (23) and a correlation exists between lipid levels and inflammation $(7,24)$, we assessed the potential effect of hepatic inflammation on both hepatic and plasma lipid levels. 

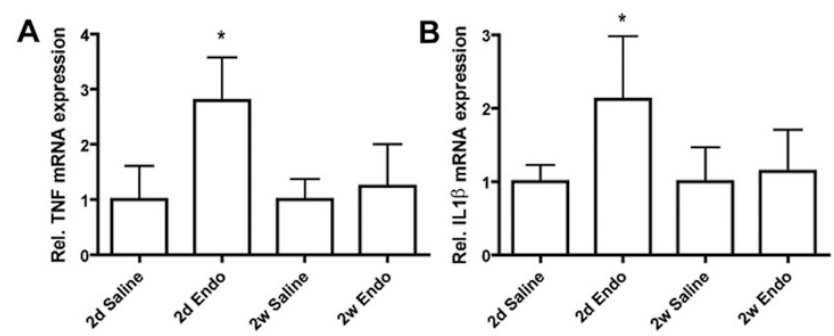

Figure 3. Hepatic gene expression analysis with quantitative RT-PCR. Cytokine mRNA levels were normalized to cyclophylin A (PPIA). Relative gene expression of TNF $(A)$ and IL-1 $\beta(B)$ in liver $2 \mathrm{~d}$ and $2 \mathrm{wk}$ after endotoxin compared with proper saline control. $* p<0.05$ significant difference from saline-injected group.

Both total cholesterol and triglycerides plasma levels were increased $2 \mathrm{~d}$ after endotoxin-induced chorioamnionitis (Fig. $4 A$ and $B$ ). The increase in cholesterol corresponds with increased HDL and LDL levels, although only HDL levels are significantly increased $2 \mathrm{~d}$ after endotoxin-induced chorioamnionitis (Fig. 4A). The increases in cholesterol and triglycerides were limited to the plasma. Two days after endotoxin exposure, preterm-delivered lambs showed hepatic cholesterol levels that tended to increase compared with control levels $(p=0.06)$. Two weeks after endotoxin injections, hepatic cholesterol returned to basal levels (Table 2). Hepatic triglycerides levels were not affected by exposure to endotoxin; this was independently confirmed by oil red $\mathrm{O}$ staining (data not shown).

A significant increase was observed in plasma glucose levels both $2 \mathrm{~d}$ and $2 \mathrm{wk}$ after the endotoxin injections (Fig. $4 D$ ). In addition, abundant glycogen storage was observed within the livers of both control groups. However, the PAS staining in hepatocytes gradually disappeared after endotoxin injections (Fig. 4C), indicating that the amount of hepatic glycogen decreases in response to endotoxin-induced chorioamnionitis (Fig. 4E-H).
Liver damage after endotoxin-induced chorioamnionitis. All groups exhibited equal antioxidant activities based on the TEAC assay, except for the group that was injected $2 \mathrm{~d}$ before delivery where we detected a decrease in the concentration of the antioxidant capacity (Fig. 5A). Similarly, the measurement of mRNA expression of GST was also decreased $2 \mathrm{~d}$ after fetal exposure to endotoxin. Two weeks after the endotoxin injection, the mRNA expression returned to basal levels (Fig. 5B). Moreover, plasma GGT levels were significantly increased both $2 \mathrm{~d}$ and $2 \mathrm{wk}$ after endotoxin injections (Fig. 5C). To assess whether the hepatic inflammatory response and lipid changes were associated with increased liver damage, the level of plasma GGT, ALT, and AST were measured. Both plasma ALT and AST measurements showed a significant increase 2 wk after endotoxin-induced chorioamnionitis (Fig. $5 D$ and $E$ ).

\section{DISCUSSION}

This study demonstrates for the first time that fetuses exposed to endotoxin-induced chorioamnionitis develop hepatic inflammation and disturbed lipid metabolism in utero. Accordingly, our data stress the importance to monitor liver function and metabolism in infants born in the setting of chorioamnionitis-induced FIRS.

Although the liver is one of the most important organs both in fetal and in adult life, studies concerning chorioamnionitisinduced FIRS are limited to lungs, brain, and gut (25-27). In previous studies, we already investigated the inflammatory response to chorioamnionitis in lungs, brain, and gut using the same fetal sheep model $(10,28)$. We have shown that endotoxin evoked a pulmonary inflammatory response $2 \mathrm{~d}$ after injections (10), which is not mediated by cortisol (29) and induced oxidative stress in the fetal lung $(27,30)$. The chorioamnionitis-induced inflammatory response in the brain was dose dependent and the most prominent in the animals that received endotoxin 2 wk before the deliv-

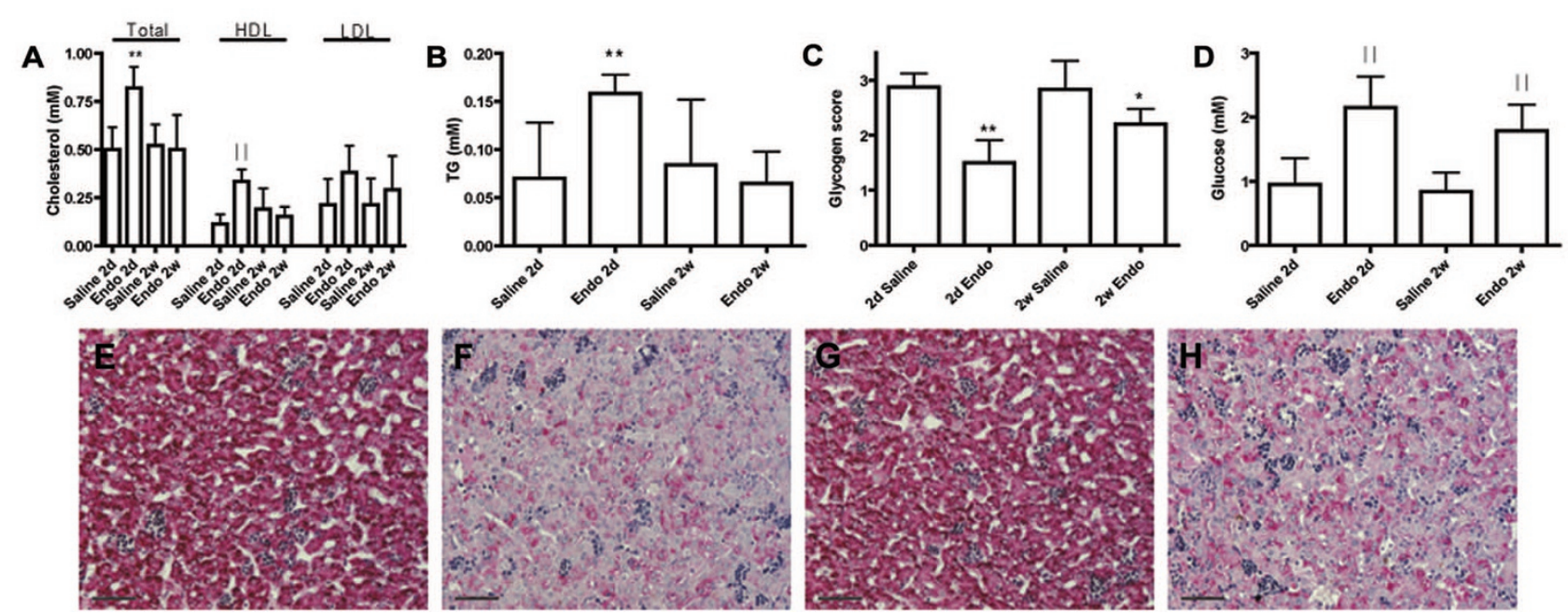

Figure 4. Metabolic parameters of saline and endotoxin-exposed animals. Plasma total cholesterol, HDL, and LDL levels $(A)$. Plasma triglycerides levels $(B)$. Plasma glucose levels $(C)$. Representative score of hepatic glycogen content from control and endotoxin-exposed animals based on PAS-stained liver sections $(D)$. Representative pictures ( $\times 200$ magnification; scale bar corresponds to $100 \mu \mathrm{m})$ of the PAS staining for the saline $2 \mathrm{~d}(E)$, endotoxin $2 \mathrm{~d}(F)$, saline $2 \mathrm{wk}$ $(G)$, and endotoxin $2 \mathrm{wk}(H)$ exposed animals, respectively. ${ }^{*} p<0.05 ; * *<0.01$; and $\| p<0.001$ significant difference from saline-injected group. 

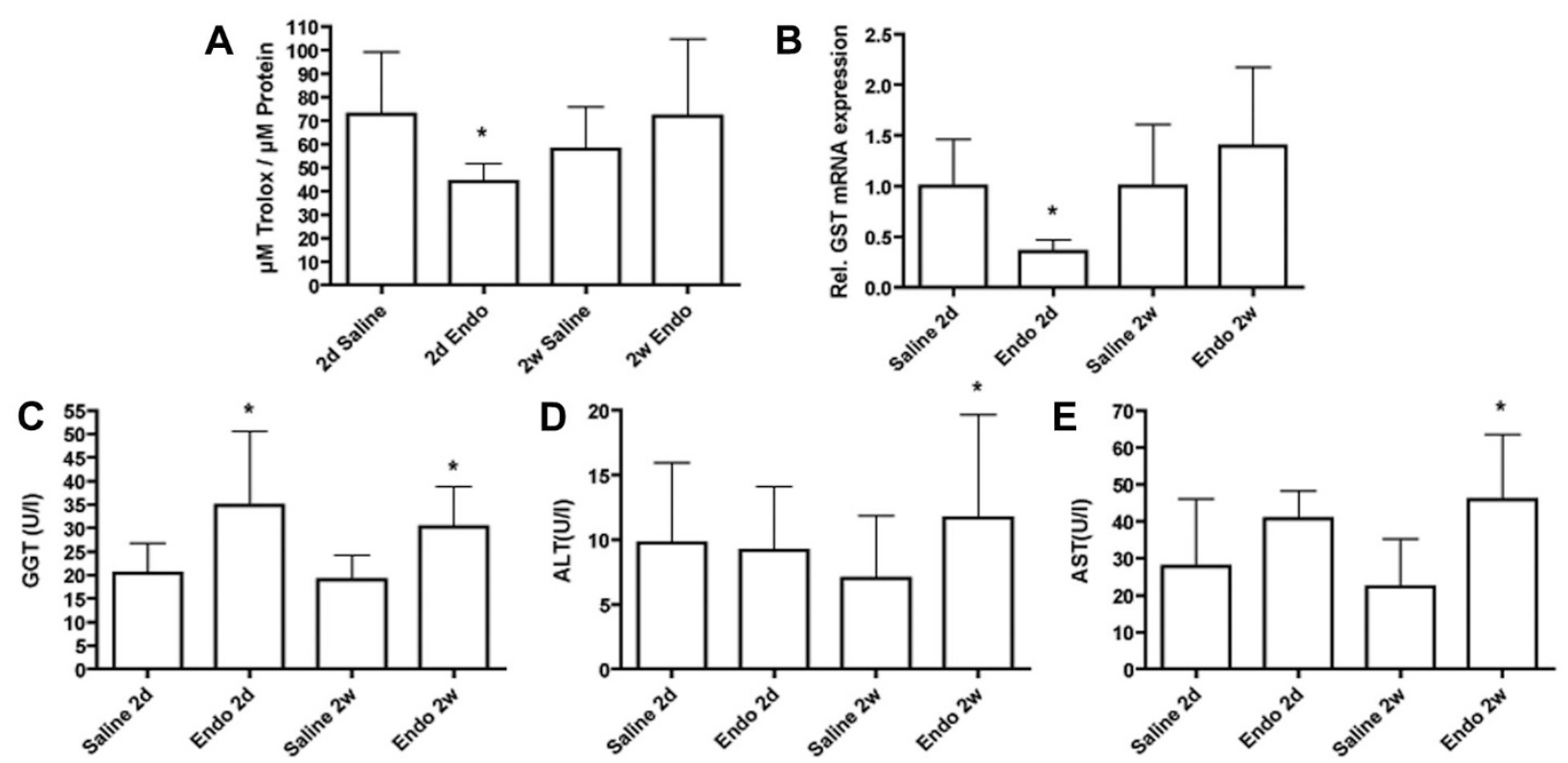

Figure 5. Quantification of oxidative stress and liver damage. TEAC assay. Overall antioxidant capacity expressed as $\mu \mathrm{M}$ Trolox/ $\mu \mathrm{g}$ protein $(A)$. Relative mRNA expression of GST $2 \mathrm{~d}$ and $2 \mathrm{wk}$ after endotoxin compared with control animals $(B)$. Plasma levels of GGT $(C)$, ALT $(D)$, and AST $(E)$, respectively $* p<0.05$ significant difference from saline-injected group.

ery (28). Comparable effects were found in the gut, where endotoxin-induced chorioamnionitis did not induce an early inflammatory response. However, 2 wk after endotoxin administration, preterm animals showed increased numbers of infiltrating inflammatory cells (25). In this study, we demonstrated for the first time that chorioamnionitis led to hepatic inflammation and disturbed fetal lipid metabolism. Although the increased inflammatory response was not associated with changes in hepatic lipid levels, plasma lipids were significantly increased.

In liver disease, activated immune cells release inflammatory mediators such as cytokines in the microenvironment of the liver (9). In good agreement, we observed a rapid and robust elevation of both IL- $1 \beta$ and TNF mRNA expression in the liver in response to neutrophil infiltration and CD3-positive T-lymphocyte expansion. IL- $1 \beta$ and TNF are well-known proinflammatory cytokines, involved in the early inflammatory response and in the evolution of the inflammatory events (31). TNF is also one of the major activators of nuclear factor kappa $\mathrm{B}$, a transcription factor that plays a crucial role in inflammation and regulates the production of TNF and multiple other cytokines (32). By promoting migration and adhesion, TNF contributes to increased infiltration of inflammatory cells, leading to a sustained inflammatory response. The observed inflammatory cell influx on H/E-, MPO-, and CD3-T-lymphocyte staining, in combination with increased cytokine expression, clearly indicate that the fetal liver is inflamed in response to the endotoxin-induced chorioamnionitis.

Several studies proposed that proinflammatory cytokines may induce metabolic changes $(33,34)$. TNF- $\alpha$ and IL-6 could inhibit lipoprotein lipase, and TNF- $\alpha$ stimulates hormone-sensitive lipase and induces uncoupling protein expression. TNF- $\alpha$ can also down-regulate insulin-stimulated glucose uptake and therefore evoke insulin resistance and inefficient carbohydrate conversion. Increased plasma triglyceride levels represent an early and consistent metabolic alteration during inflammation. In addition, increased plasma total cholesterol levels and hepatic cholesterol synthesis has been reported (9). In our study, we indeed observed a similar peak in cholesterol and triglycerides levels in combination with the hepatic inflammatory response $2 \mathrm{~d}$ after exposure to endotoxin. These changes in lipid metabolism serve as first line defense against the induced inflammation, as the effects of cytokines on lipid metabolism are direct. However, in cases of chronic inflammation, the cytokine-induced lipid changes could be deleterious and may contribute to the development of metabolic diseases (9). Surprisingly, the early (i.e. $2 \mathrm{~d}$ postinjection) rise in lipid levels did not persist. This unexpected observation could be attributed to the apparent ability of the fetus to modulate and down-regulate lipid levels $(13,35)$. Although the changes in lipid levels seem to be resolved $2 \mathrm{wk}$ after the endotoxin injections, this issue needs further investigation as the inflammation persisted. Indeed, as inflammation is thought to induce marked changes in lipid metabolism (9), a potential long-term effect may be the development of metabolic disease. The observed increases in plasma glucose levels after $2 \mathrm{~d}$ and 2 wk endotoxin treatment are in line with the decreases in glycogen content observed by PAS-staining. Similarly, it was shown that endotoxin treatment in mice can diminish liver glycogen content as early as $1 \mathrm{~h}$ after treatment, probably because of impairment of glycogenesis and gluconeogenesis (36).

In addition to the lipid changes and hepatic inflammation, endotoxin-induced chorioamnionitis also led to oxidative damage. Oxidative damage to tissues has been implicated in the pathogenesis of liver disease (18); we here show evidence 
of immediate and sustained oxidative damage by the immunohistochemical staining against MPO. MPO is an important enzyme that is stored in azurophilic granules of polymorphonuclear (PMN) neutrophils and is therefore used as a neutrophil marker (37). In addition, hepatic infiltration of MPOpositive PMN neutrophils is associated with the presence of oxidized phospholipids (38). Therefore, the presence of MPOmediated lipid oxidation is indicative of altered lipid metabolism leading to further hepatic damage.

Additional evidence for an altered redox/oxidative status in the livers of these fetuses was the decreased expression of GST $2 \mathrm{~d}$ after the endotoxin injections and the reduced capacity of the trolox assays. GST is an enzymatic antioxidant that is released by neutrophils and macrophages at sites of inflammation and its activity protects cells against oxidative stress $(39,40)$. The level of antioxidant capacity may provide a clear indication on the extent of cytotoxic damage that occurs in the liver (41). Oxidative stress can overwhelm the antioxidant defense mechanisms and perturb the structure and functions of the fetal liver $(39,40)$. The early down-regulation of GST expression we observe suggests that the fetus may have difficulties in responding to oxidative stress. Indeed, the decrease in antioxidant capacity in the liver of these fetuses was associated with liver damage indicated by the increase in plasma GGT levels. In addition, both plasma ALT and AST levels were increased 2 wk after fetal exposure to endotoxin, indicating the presence of persisting liver damage, varying cell viability, and cell membrane permeability in these fetal sheep (41).

In summary, this study demonstrates for the first time that chorioamnionitis-induced FIRS can sensitize the fetus to develop hepatic inflammation, consequently leading to metabolic disturbances. Moreover, these metabolic changes could lead to further development of hepatic inflammation and even insulin resistance in later life $(42,43)$. The underlying mechanisms of these findings and the long-term effects of chorioamnionitis require further studies. However, our results already suggest an important clinical indication to monitor liver function and metabolism in chorioamnionitis-affected babies.

Acknowledgments. We thank Claudia Clorefice (Department of Clinical Chemistry, Maastricht University Medical Center), Sonia Garcia (Department of Anatomy and Embryology), and Roger Bartholomez (Department of Pharmacology and Toxicology) for helping us with the measurements, and Tim Wolfs (Department of Pediatrics, Maastricht University) for giving technical advice about the immunohistochemical stainings.

\section{REFERENCES}

1. Behrman R, Butler A 2007 Preterm Birth: Causes, Consequences, and Prevention. The National Academies Press, Washington, DC

2. Goldenberg RL, Hauth JC, Andrews WW 2000 Intrauterine infection and preterm delivery. N Engl J Med 342:1500-1507

3. Bibby E, Stewart A 2004 The epidemiology of preterm birth. Neuroendocrinol Lett 25:43-47

4. Steel JH, Malatos S, Kennea N, Edwards AD, Miles L, Duggan P, Reynolds PR, Feldman RG, Sullivan MH 2005 Bacteria and inflammatory cells in fetal membranes do not always cause preterm labor. Pediatr Res 57:404-411
5. Romero R, Espinoza J, Chaiworapongsa T, Kalache K 2002 Infection and prematurity and the role of preventive strategies. Semin Neonatol 7:259-274

6. Gotsch F, Romero R, Kusanovic JP, Mazaki-Tovi S, Pineles BL, Erez O, Espinoza J, Hassan SS 2007 The fetal inflammatory response syndrome. Clin Obstet Gynecol 50:652-683

7. Wouters K, van Gorp PJ, Bieghs V, Gijbels MJ, Duimel H, Lutjohann D, Kerksiek A, van Kruchten R, Maeda N, Staels B, van Bilsen M, Shiri-Sverdlov R, Hofker MH 2008 Dietary cholesterol, rather than liver steatosis, leads to hepatic inflammation in hyperlipidemic mouse models of nonalcoholic steatohepatitis. Hepatology 48:474486

8. Shiri-Sverdlov R, Wouters K, van Gorp PJ, Gijbels MJ, Noel B, Buffat L, Staels B, Maeda N, van Bilsen M, Hofker MH 2006 Early diet-induced non-alcoholic steatohepatitis in APOE2 knock-in mice and its prevention by fibrates. J Hepatol 44:732-741

9. Khovidhunkit W, Kim MS, Memon RA, Shigenaga JK, Moser AH, Feingold KR, Grunfeld C 2004 Effects of infection and inflammation on lipid and lipoprotein metabolism: mechanisms and consequences to the host. J Lipid Res 45:1169-1196

10. Kramer BW, Moss TJ, Willet KE, Newnham JP, Sly PD, Kallapur SG, Ikegami M, Jobe AH 2001 Dose and time response after intraamniotic endotoxin in preterm lambs. Am J Respir Crit Care Med 164:982-988

11. Kramer BW, Kaemmerer U, Kapp M, Herbst D, Marx A, Berg D, Groneck PA, Speer CP 2005 Decreased expression of angiogenic factors in placentas with chorioamnionitis after preterm birth. Pediatr Res 58:607-612

12. Kramer BW, Ikegami M, Jobe AH 2002 Intratracheal endotoxin causes systemic inflammation in ventilated preterm lambs. Am J Respir Crit Care Med 165:463-469

13. Kramer BW, Jobe $\mathrm{AH} 2005$ The clever fetus: responding to inflammation to minimize lung injury. Biol Neonate 88:202-207

14. Kramer BW, Kramer S, Ikegami M, Jobe AH 2002 Injury, inflammation, and remodeling in fetal sheep lung after intra-amniotic endotoxin. Am J Physiol Lung Cell Mol Physiol 283:L452-L459

15. Kallapur SG, Willet KE, Jobe AH, Ikegami M, Bachurski CJ 2001 Intra-amniotic endotoxin: chorioamnionitis precedes lung maturation in preterm lambs. Am J Physiol Lung Cell Mol Physiol 280:L527-L536

16. Newnham JP, Kallapur SG, Kramer BW, Moss TJ, Nitsos I, Ikegami M, Jobe AH 2003 Betamethasone effects on chorioamnionitis induced by intra-amniotic endotoxin in sheep. Am J Obstet Gynecol 189:1458-1466

17. Baron MH 2001 Embryonic induction of mammalian hematopoiesis and vasculogenesis. In: Zon LI (ed) Hematopoiesis-A Developmental Approach. Oxford University Press, Inc., Oxford, England, pp 162-170

18. Klebanoff SJ 2005 Myeloperoxidase: friend and foe. J Leukoc Biol 77:598-625

19. Fischer MA, Gransier TJ, Beckers LM, Bekers O, Bast A, Haenen GR 2005 Determination of the antioxidant capacity in blood. Clin Chem Lab Med 43:735-740

20. Tsunoda K, Hamato S, Kurosawa S, Shirato A, Kurosawa Y, Fujimaki K, Muto M, Sato K 2002 Apolipoprotein C polymorphism in sheep: allele frequencies and association with plasma lipid and lipoprotein levels. Biochem Genet 40:27-39

21. Uyanik F 2001 The effects of dietary chromium supplementation on some blood parameters in sheep. Biol Trace Elem Res 84:93-101

22. Friedewald WT, Levy RI, Fredrickson DS 1972 Estimation of the concentration of low-density lipoprotein cholesterol in plasma, without use of the preparative ultracentrifuge. Clin Chem 18:499-502

23. Neville MC 1999 Adaptation of maternal lipid flux to pregnancy: research needs. Eur J Clin Nutr 53:S120-S123

24. Tilg H, Hotamisligil GS 2006 Nonalcoholic fatty liver disease: cytokine-adipokine interplay and regulation of insulin resistance. Gastroenterology 131:934-945

25. Wolfs TG, Buurman WA, Zoer B, Moonen RM, Derikx JP, Thuijls G, Villamor E, Gantert M, Garnier Y, Zimmermann LJ, Kramer BW 2009 Endotoxin induced chorioamnionitis prevents intestinal development during gestation in fetal sheep. PLoS ONE 4:e5837

26. Gavilanes AW, Gantert M, Strackx E, Zimmermann LJ, Seeldrayers S, Vles JS, Kramer BW 2010 Increased EEG delta frequency corresponds to chorioamnionitisrelated brain injury. Front Biosci (Schol Ed) 2:432-438

27. Sosenko IR, Jobe AH 2003 Intraamniotic endotoxin increases lung antioxidant enzyme activity in preterm lambs. Pediatr Res 53:679-683

28. Gavilanes AW, Strackx E, Kramer BW, Gantert M, Van den Hove D, Steinbusch H, Garnier Y, Cornips E, Steinbusch H, Zimmermann L, Vles J 2009 Chorioamnionitis induced by intraamniotic lipopolysaccharide resulted in an interval-dependent increase in central nervous system injury in the fetal sheep. Am J Obstet Gynecol 200:437.e1-e8

29. Jobe AH, Newnham JP, Willet KE, Moss TJ, Gore Ervin M, Padbury JF, Sly P, Ikegami M 2000 Endotoxin-induced lung maturation in preterm lambs is not mediated by cortisol. Am J Respir Crit Care Med 162:1656-1661

30. Cheah FC, Jobe AH, Moss TJ, Newnham JP, Kallapur SG 2008 Oxidative stress in fetal lambs exposed to intra-amniotic endotoxin in a chorioamnionitis model. Pediatr Res 63:274-279

31. Caille V, Bossi P, Grimaldi D, Vieillard-Baro A 2004 [Physiopathology of severe sepsis]. Presse Med 33:256-261; discussion 269

32. Tacke F, Luedde T, Trautwein C 2009 Inflammatory pathways in liver homeostasis and liver injury. Clin Rev Allergy Immunol 36:4-12

33. Mundt B, Wirth T, Zender L, Waltemathe M, Trautwein C, Manns MP, Kuhnel F, Kubicka S 2005 Tumour necrosis factor related apoptosis inducing ligand (TRAIL) induces hepatic steatosis in viral hepatitis and after alcohol intake. Gut 54:15901596

34. Chikano S, Sawada K, Shimoyama T, Kashiwamura SI, Sugihara A, Sekikawa K, Terada N, Nakanishi K, Okamura H 2000 IL-18 and IL-12 induce intestinal inflammation and fatty liver in mice in an IFN-gamma dependent manner. Gut 47:779-786 
35. West MA, Heagy W 2002 Endotoxin tolerance: a review. Crit Care Med 30:S64S73

36. Villar-Palasi C, Larner J 1970 Glycogen metabolism and glycolytic enzymes. Annu Rev Biochem 39:639-672

37. Loria V, Dato I, Graziani F, Biasucci LM 2008 Myeloperoxidase: a new biomarker of inflammation in ischemic heart disease and acute coronary syndromes. Mediators Inflamm 2008:135625

38. Rensen SS, Slaats Y, Nijhuis J, Jans A, Bieghs V, Driessen A, Malle E, Greve JW, Buurman WA 2009 Increased hepatic myeloperoxidase activity in obese subjects with nonalcoholic steatohepatitis. Am J Pathol 175:1473-1482
39. Saugstad OD 2005 Oxidative stress in the newborn-a 30-year perspective. Biol Neonate 88:228-236

40. Sato EF, Nakagawa E, Hiramoto K, Yamamasu S, Moriyama-Shimamoto I, Inoue M 2004 Oxidative stress promotes the regression of fetal liver hemopoiesis. Biochemistry (Mosc) 69:18-22

41. Pari L, Prasath A 2008 Efficacy of caffeic acid in preventing nickel induced oxidative damage in liver of rats. Chem Biol Interact 173:77-83

42. Ruvolo PP 2003 Intracellular signal transduction pathways activated by ceramide and its metabolites. Pharmacol Res 47:383-392

43. Browning JD, Horton JD 2004 Molecular mediators of hepatic steatosis and liver injury. J Clin Invest 114:147-152 